\title{
A needs assessment of resuscitative endovascular balloon occlusion of the aorta (REBOA) in non-traumatic out-of-hospital cardiac arrest in Norway
}

\author{
Jostein Rødseth Brede ${ }^{1,2,3,4^{*}}$, Jo Kramer-Johansen ${ }^{5,6,7}$ and Marius Rehn $n^{2,5,8}$
}

\begin{abstract}
Introduction: Out of hospital cardiac arrest (OHCA) carries an 86\% mortality rate in Norway. Resuscitative endovascular balloon occlusion of the aorta (REBOA) is a potential adjunct in management of non-traumatic cardiac arrest and is feasible in pre-hospital setting without compromising standard cardiopulmonary resuscitation (CPR). However, number of patients potentially eligible for REBOA remain unknown. In preparation for a clinical trial to investigate any benefit of pre-hospital REBOA, we sought to assess the need for REBOA in Norway as an adjunct treatment in OHCA.

Methods: Retrospective observational cohort study of data from the Norwegian Cardiac Arrest Registry in the 3year period 2016-2018. We identified number of patients potentially eligible for pre-hospital REBOA during CPR, defined by suspected non-traumatic origin, age 18-75 years, witnessed arrest, ambulance response time less than $15 \mathrm{~min}$, treated by ambulance personnel and resuscitation effort over $30 \mathrm{~min}$.

Results: In the 3-year period, ambulance personnel resuscitated 8339 cases. Of these, a group of 720 patients (8.6\%) were eligible for REBOA. Only $18 \%$ in this group achieved return of spontaneous circulation and $7 \%$ survived for 30 days or more.

Conclusion: This national registry data analysis constitutes a needs assessment of REBOA in OHCA. We found that each year approximately 240 patients, or nearly $9 \%$ of ambulance treated OHCA, in Norway is potentially eligible for pre-hospital REBOA as an adjunct treatment to standard resuscitation. This needs assessment suggests that there is sufficient patient population in Norway to study REBOA as an adjunct treatment in OHCA.
\end{abstract}

Keywords: Aortic occlusion, Cardiac arrest, Cardiopulmonary resuscitation, REBOA

\section{Background}

Of all patients treated for out of hospital cardiac arrest (OHCA) in Norway, one third regains spontaneous circulation (ROSC), but overall, $86 \%$ don't survive [1].

\footnotetext{
* Correspondence: Jostein.brede@norskluftambulanse.no

'Department of Emergency Medicine and Pre-Hospital Services, St. Olav University Hospital, Trondheim, Norway

${ }^{2}$ Norwegian Air Ambulance Foundation, Department of Research and Development, Oslo, Norway

Full list of author information is available at the end of the article
}

Oxygen delivery to the brain and heart are pivotal and maintenance of circulation with cardio-pulmonary resuscitation (CPR) is beneficial, but often futile if the precipitating cause of arrest cannot be identified and remedied. The number of OHCA in Norway was 3172 in 2017, which correlates to an OHCA incidence of 60/100000 inhabitants per year, increasing from 53/100000 in 2015 [1]. Many patients with OHCA carry little comorbidity

C C The Author(s). 2020 Open Access This article is licensed under a Creative Commons Attribution 4.0 International License, which permits use, sharing, adaptation, distribution and reproduction in any medium or format, as long as you give appropriate credit to the original author(s) and the source, provide a link to the Creative Commons licence, and indicate if changes were made. The images or other third party material in this article are included in the article's Creative Commons licence, unless indicated otherwise in a credit line to the material. If material is not included in the article's Creative Commons licence and your intended use is not permitted by statutory regulation or exceeds the permitted use, you will need to obtain permission directly from the copyright holder. To view a copy of this licence, visit http://creativecommons.org/licenses/by/4.0/. The Creative Commons Public Domain Dedication waiver (http://creativecommons.org/publicdomain/zero/1.0/) applies to the data made available in this article, unless otherwise stated in a credit line to the data. 
with potential for good long-term functional recovery [2].

Resuscitative endovascular balloon occlusion of the aorta (REBOA) can be applied in management of haemorrhagic shock or cardiac arrest (CA) secondary to trauma. Further, REBOA has been advocated as an adjunct in management of non-traumatic cardiac arrest patients [3, 4]. Animal studies show that REBOA during cardiopulmonary resuscitation (CPR) provide both increased coronary artery blood flow and perfusion pressure and increased rates of return of spontaneous circulation (ROSC) [5-11]. In humans, increased coronary perfusion pressure is associated with ROSC [12]. REBOA during experimental CPR also increase blood flow to the carotids $[8,13]$, and cerebral arteries $[6,7$, 13-15] with subsequent increased cerebral perfusion pressure $[6,7,13,16]$. Hence, patients with nontraumatic CA might benefit from REBOA during CPR. Currently, only one study reports the prospective use of REBOA in clinical use [17]. This study demonstrates that pre-hospital REBOA procedure during resuscitation is feasible and does not influence advanced cardiovascular life support (ACLS).

Several studies estimate number of patients with potential benefit from REBOA in treatment of haemorrhagic trauma [18-20]. However, no study has yet reported number of cardiac arrest patients that potentially may benefit from pre-hospital REBOA. Whether REBOA or any other invasive procedure applied late in resuscitation scenario, improves outcome for OHCA patients remain unknown but should be investigated in clinical trials. In preparation for such a trial, we sought to assess the number of patients eligible for REBOA as an adjunct treatment in OHCA, with the use of data from the Norwegian Cardiac Arrest Registry (NORCAR).

\section{Methods}

This is a retrospective observational cohort study following the STROBE guideline [21], on adult patient data (age 18-75 years) captured in NORCAR in the 3-year period January 1st 2016 to December 31st 2018. NORCAR is a mandatory national health registry, hosted by Oslo University Hospital. The registry aim to monitor and improve healthcare provided to people with cardiac arrest. The registry is a resuscitation registry and all patients treated by bystanders or health care professionals with CPR or defibrillation are included. All Norwegian health trusts reports OHCA to this registry into a central database (Medical Registry System) that ensures data integrity, privacy and security [1]. NORCAR captures data based on a modified Utstein template on patient and event characteristics, as well as treatment and outcomes grouped by Emergency Medical Communications Centre (EMCC), ambulance services, and hospitals.

Centrality index reflects a municipality's degree of centrality. It is calculated by Statistics Norway based on travel time to workplaces and high-order service functions and the result is grouped in categories from 1 (most central) to 6 (least central) [22].

NORCAR can extract and prepare aggregated, anonymous results without further ethical approval. A NORCAR administrator (JKJ) extracted, recoded and aggregated the data on request from the main author (Norwegian Institute of Public Health, ref.nr HKR 190149).

\section{Preprocessing of data}

We recoded the municipality where the event took place, into centrality category from 1 (most central) to 6 (least central) based upon data from Statistics Norway [22].

We calculated ambulance response intervals as the time interval between first call received at EMCC to the time when the first ambulance was at the patient's location. For ambulance witnessed arrests, response interval was set to zero. We regarded negative or no values for response interval as missing values. We excluded cases with response intervals exceeding $120 \mathrm{~min}$.

CPR duration was calculated as the time interval from when CPR started to the time CPR ended. If "Time CPR started" was missing, we did the following exchanges: 1 . If cardiac arrest was witnessed by the ambulance, we used "Time of cardiac arrest" as "Time CPR started". 2. If the first rhythm was registered as ventricular fibrillation (VF) or ventricular tachycardia (VT), we used "Time first defibrillation" as "Time CPR started".

If "Time CPR ended" was missing, we did the following exchanges: 1 . If the patient had ROSC, we used "Time sustained ROSC" as "Time CPR ended". 2. If patient arrived at hospital with ongoing CPR, we used "Time arrived at hospital" as "Time CPR ended". We regarded negative values and no values for CPR duration as missing values. We excluded cases with CPR duration of more than $120 \mathrm{~min}$. The time limit on response interval and CPR duration enabled a valid data extraction from the registry.

\section{Data extraction and filtering}

We analyzed data in sub-groups as presented in the flowchart in Fig. 1. The data is split into three groups, based on duration of CPR; CPR duration less than 15 min (never eligible), CPR duration from 15 to $29 \mathrm{~min}$ (potentially eligible), and CPR duration longer than 30 min (eligible). 


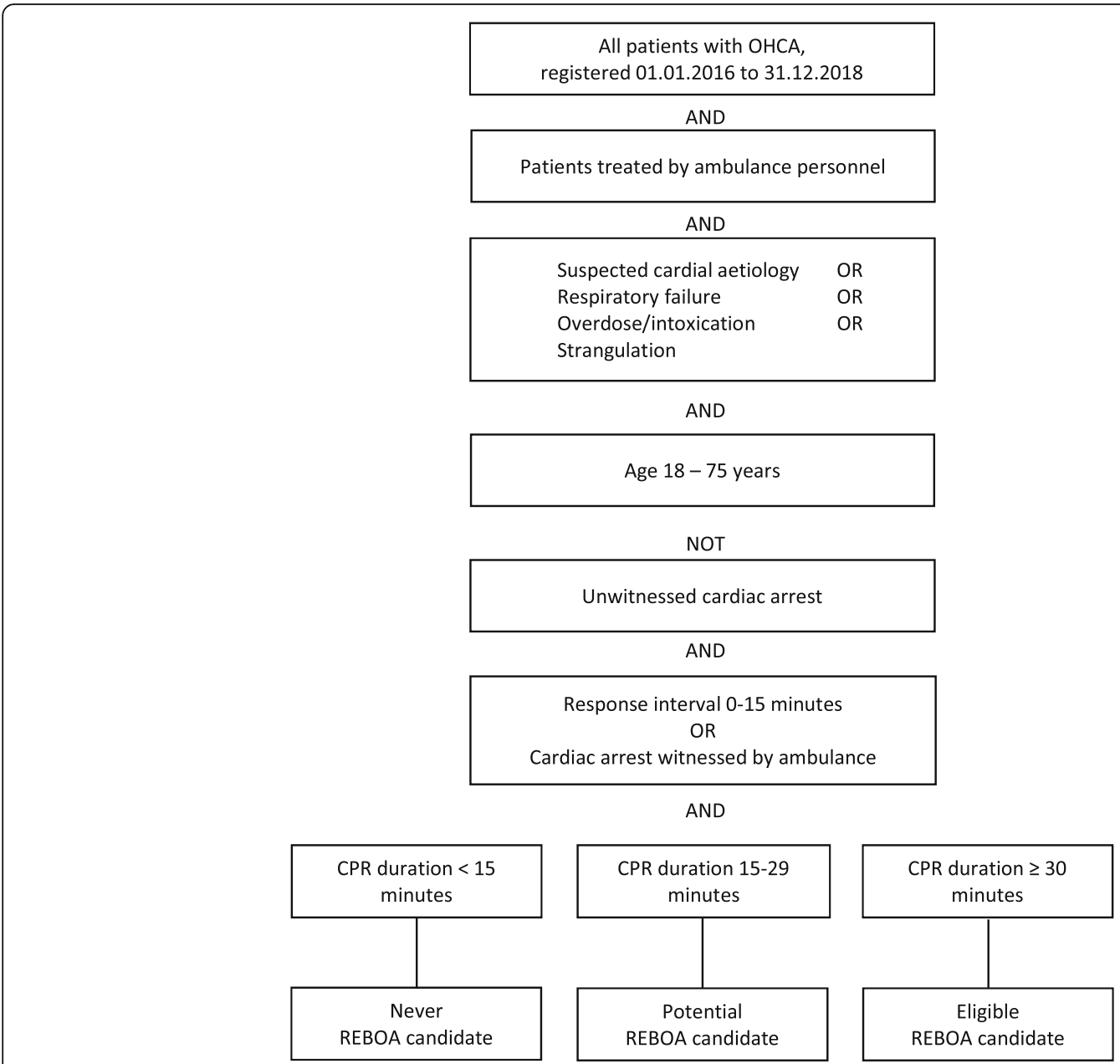

Fig. 1 Data extraction from the Norwegian Cardiac Arrest Registry followed this flowchart. OHCA, out of hospital cardiac arrest. CPR, cardiopulmonary resuscitation. REBOA, resuscitative endovascular balloon occlusion of the aorta

Table 1 The characteristics of all patients with OHCA in the Norwegian Cardiac Arrest Registry from 2016 to 2018 (3 years). OHCA, out of hospital cardiac arrest. IQR, interquartile range. CPR, cardiopulmonary resuscitation

\begin{tabular}{|c|c|c|}
\hline Characteristics & Missing data & Number of patients \\
\hline All patients with $\mathrm{OHCA}(\mathrm{n})$ & & 10,488 \\
\hline Age (median, IQR) & & $69(54-79)$ \\
\hline Gender (\% male) & & 66 \\
\hline Treated by ambulance personnel ( $n$ ) & & 8339 \\
\hline Non traumatic arrests $(n)$ & & 7551 \\
\hline Age $18-75(n)$ & 5 & 4596 \\
\hline Age (median, IQR) & & $62(52-69)$ \\
\hline Gender (\% male) & & 71 \\
\hline Witnessed collapse (n) & 106 & 2772 \\
\hline Treated by ambulance personnel within $15 \mathrm{~min}(\mathrm{n})$ & 35 & 2241 \\
\hline CPR duration (n) & 277 & \\
\hline$<15 \min$ & & 716 \\
\hline $15-29 \min$ & & 528 \\
\hline$>30 \mathrm{~min}$ & & 720 \\
\hline
\end{tabular}




\section{Statistical analysis}

Continuous variables are reported as median with interquartile range (IQR 1-3). Categorical variables are described as count and/or proportion (\%). Statistical analyses are performed with SPSS (IBM Corp. Released 2017. IBM SPSS Statistics for Windows, Version 25.0. Armonk, NY: IBM Corp). Proportions are analyzed with Chi-squared tests and continuous measures with Kruskal-Wallis test. A $P$ value of $<0.05$ was regarded as statistically significant.

\section{Results}

In the 3-year period 2016-2018 a total number of 10 , 488 OHCA were registered. Figure 1 and Table 1 depict results of stepwise data analyses.

We excluded 2149 patients that were not treated by ambulance personnel. Nine hundred seventeen cases were considered futile, 71 cases had do-not-resuscitate status, in 65 cases resuscitation was aborted due to preexisting comorbidity, in 989 cases circulation was detected at ambulance arrival and in 107 cases no reason for not treating the patient was reported. Secondly, we filtered based on presumed cause of arrest and excluded 788 patients. The presumed cause was neurological in 168 cases, drowning in 128 cases, non-traumatic hemorrhage in 162 cases, hypothermia in 12 cases, fire/ trauma in 293 cases and sudden infant death syndrome in 25 cases. After restricting age range and excluding non-witnessed cases, we grouped 2241 cases with response interval shorter than $15 \mathrm{~min}$, into three groups based on CPR duration (Table 2).

Table 2 shows that the three groups have minor differences in gender, age, response interval and presumed cause of arrest, with cardiac aetiology as the most frequent cause. There is a high proportion of bystander CPR (> 80\%) before ambulance arrival in all groups. Figure 2 shows that there is a greater proportion of shockable initial rhythm in the group with shortest CPR duration.

Figure 3 show the distribution of centrality class in the three subgroups (class 1 being most central). In the group eligible for REBOA, most cases are from central areas, with only $16 \%$ of cases from the least central areas (class 5-6).

A distinct decrease in ROSC and 30-day survival in the three subgroups are shown in Fig. 4. In the group with CPR duration more than $15 \mathrm{~min}$ (eligible group), $18 \%$ of patient achieve ROSC and $7 \%$ survive for 30 days or more.

\section{Discussion}

This is the first study to report the estimated number of potentially eligible patients for REBOA in OHCA. Our analysis demonstrates that over a three-year period 720 patients in Norway were potentially eligible. This corresponds to 240 patients per year or approximately $9 \%$ of the total number of ambulance treated OHCA. The patient group is predominately young with a median age of 65 years with a high potential for good long-term functionality.

The 30-day survival rate of the total OHCA patients in Norway in the period of observation is $14 \%$, and $83 \%$ of these patients had good neurological outcome, measured as Cerebral Performance Category 1 or 2 [1], a scale often used to assess neurological outcome after cardiac arrest $[23,24]$. Studies report that few OHCA patients overall have terminal illness and most have no or mild comorbidity [2, 25]. Pre-hospital healthcare providers are faced with the question of when to continue or terminate a resuscitation attempt, mostly without knowledge of any previous "do-not-resuscitate" decisions or absolute "termination-of-resuscitation"-rules. We commonly accept that the decision to stop resuscitation rely on the healthcare providers qualitative judgement [26]. The guidelines from the Norwegian Resuscitation Council recommend to continue CPR if there is persistent $\mathrm{VF} / \mathrm{VT}$, hypothermia, or as long as ethical/medical justifiable or signs of life [27]. Age is a factor that is easily obtained during resuscitation and is associated with increasing comorbidity and reduced life expectancy. Patient age has been associated with healthcare providers feelings of inappropriate CPR efforts [28]. However, one study report that older patients ( $>70$ years) may survive OHCA with favorable neurological outcome and that most have only mild or moderate comorbidity [29]. This clearly indicates that age alone is not a reliable argument to decide if the resuscitation is ethically or medically justifiable. Accordingly, we found it reasonable to include patients up to 75 years of age in this assessment of eligibility for pre-hospital REBOA in OHCA.

The differences between the groups (Table 2) reflects the selection process based on CPR duration where it is reasonable to expect characteristics associated with favorable prognosis to be more prevalent among those with shorter CPR duration. Further exploration of these associations with multi-variate regression analysis is beyond the scope of this study.

Survival rates declines even after few minutes of CPR, [30] and in an unwitnessed arrest it is impossible to establish length of no-flow time. Unwitnessed cardiac arrests and unknown time of cardiac arrest was accordingly excluded from the analyses.

Twenty percent of the Norwegian population lives in rural areas, mountainous and coastal remote regions with limited access by road [31]. In our study, 16\% of eligible patients had OHCA in the most remote municipalities (class 5-6). In a sub-arctic climate, this can entail time-consuming response with weather-dependent flight 
Table 2 Characteristics and outcome in three subgroups of patients. Response interval and bystander CPR proportion are only calculated for non-ambulance witnessed arrest. Group differences in age and response interval are analyzed with Kruskal-Wallis test. Gender, presumed cause of arrest (cardiac vs non-cardiac) and bystander CPR started are analyzed with Chi-square test. Post-hoc tests are performed between specific groups and all $p$-values are corrected for multiple testing by Bonferroni correction. Only significant $\mathrm{p}$-values are reported. CPR, cardiopulmonary resuscitation. IQR, interquartile range. VFNT, ventricular fibrillation/ventricular tachycardia. PEA, pulseless electrical activity. ROSC, return of spontaneous circulation

\begin{tabular}{|c|c|c|c|c|}
\hline & $\begin{array}{l}\text { Group } 1 \\
\text { CPR duration }\end{array}$ & $\begin{array}{l}\text { Group } 2 \\
\text { CPR duration }\end{array}$ & $\begin{array}{l}\text { Group } 3 \\
\text { CPR duration }\end{array}$ & $\begin{array}{l}\text { Statistical } \\
\text { tests }\end{array}$ \\
\hline & $<15 \min$ & $15-29 \mathrm{~min}$ & $>30 \mathrm{~min}$ & \\
\hline$n$ & 716 & 528 & 720 & \\
\hline Male, n (\%) & $544(76)$ & $358(68)$ & $522(73)$ & $\begin{array}{l}P<0.05 \\
1 \text { vs } 2, P=0.004\end{array}$ \\
\hline Age, median (IQR) & $61(52-69)$ & $65(55-70)$ & $65(56-70)$ & $\begin{array}{l}P<0.01 \\
1 \text { vs } 2, P<0.001 \\
1 \text { vs } 3, P<0.001\end{array}$ \\
\hline Arrest witnessed by ambulance, $\mathrm{n}(\%)$ & $233(33)$ & $96(18)$ & $180(25)$ & $\begin{array}{l}P<0.001 \\
1 \text { vs } 2, P<0.001 \\
1 \text { vs } 3, P=0.006 \\
2 \text { vs } 3, P=0.01\end{array}$ \\
\hline Response time (min), median (IQR) & $7(5-10)$ & $8(6-11)$ & $9(7-12)$ & $\begin{array}{l}P<0.01 \\
1 \text { vs } 3, P<0.001 \\
2 \text { vs } 3, P<0.001\end{array}$ \\
\hline CPR duration (min), median (IQR) & $6(3-11)$ & $22(19-26)$ & $55(35-55)$ & \\
\hline Presumed cause, n (\%) & & & & $P=0.01$ \\
\hline Cardiac & $569(80)$ & $391(74)$ & $583(81)$ & Post-hoc tests \\
\hline Respiratory & $89(12)$ & $86(16)$ & $101(14)$ & non-significant \\
\hline Overdose/intoxication & $28(4)$ & $24(5)$ & $17(2)$ & \\
\hline Strangulation & $30(4)$ & $27(5)$ & $19(3)$ & \\
\hline Bystander CPR, n (\%) & $422(87)$ & $353(82)$ & $437(81)$ & $\begin{array}{l}P=0.01 \\
1 \text { vs } 2, P=0.05 \\
1 \text { vs } 3, P=0.02\end{array}$ \\
\hline \multicolumn{5}{|l|}{ Initial rhythm, n (\%) } \\
\hline VFNT & $427(60)$ & $171(32)$ & $275(38)$ & \\
\hline PEA & $121(17)$ & $126(24)$ & $163(23)$ & \\
\hline Asystole & $105(15)$ & $214(41)$ & $251(35)$ & \\
\hline Unknown & $63(9)$ & $17(3)$ & $31(4)$ & \\
\hline \multicolumn{5}{|l|}{ Centrality class, n (\%) } \\
\hline 1 (most central) & $204(28)$ & $120(23)$ & $127(18)$ & \\
\hline 2 & $121(17)$ & $88(17)$ & $99(14)$ & \\
\hline 3 & $161(22)$ & $134(25)$ & $181(25)$ & \\
\hline 4 & $90(13)$ & $66(13)$ & $114(16)$ & \\
\hline 5 & $44(6)$ & $38(7)$ & $85(12)$ & \\
\hline 6 (least central) & $11(2)$ & $6(1)$ & $28(4)$ & \\
\hline missing & $85(12)$ & $66(13)$ & $86(12)$ & \\
\hline Sustained ROSC, n (\%) & $609(85)$ & $251(48)$ & $132(18)$ & \\
\hline 30-day survival, n (\%) & $459(64)$ & $102(19)$ & $52(7)$ & \\
\hline
\end{tabular}

conditions. The EMCC dispatch regular ambulances and 18 helicopter emergency medical services (HEMS) units that covers the whole population [32]. Ambulance response intervals are generally short in Norway with a national median of 9 min [1], but HEMS units may have longer response intervals depending on patient location, other current missions or weather conditions. Ambulance response intervals longer than $15 \mathrm{~min}$ were excluded to avoid the potential bias of early withdrawal of care due to perceived futility. 


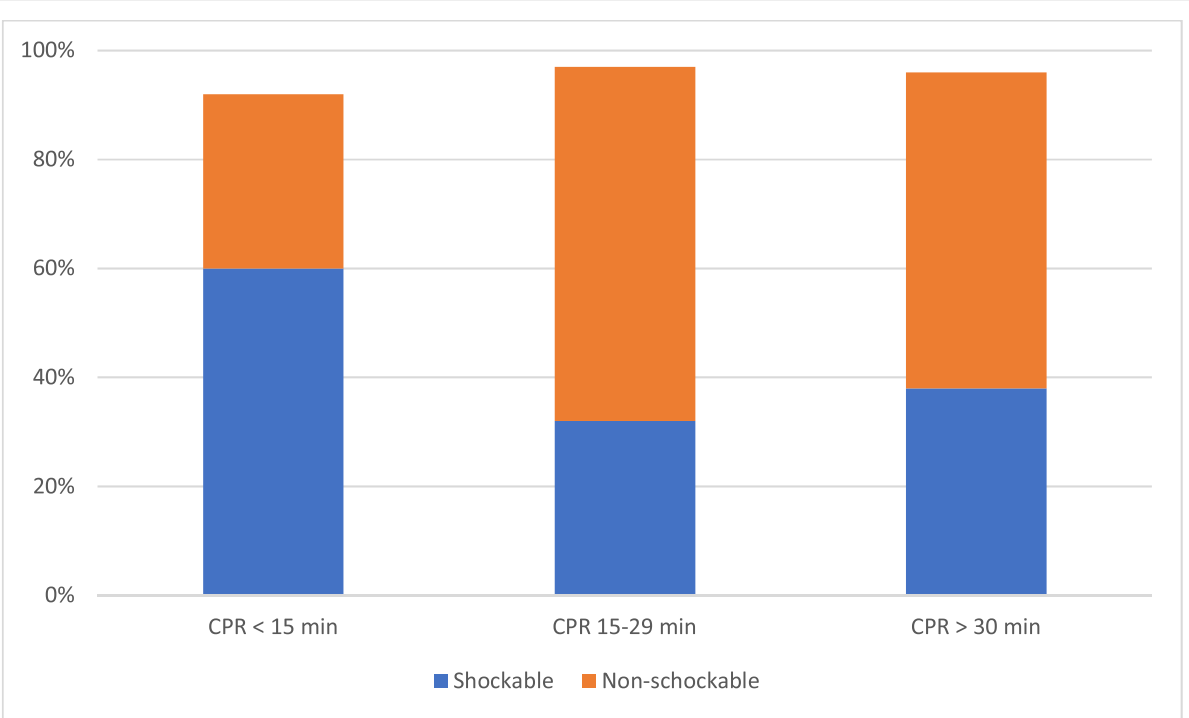

Fig. 2 Proportions of initial rhythm in the three subgroups. Cases with missing initial rhythm is not shown. CPR, cardiopulmonary resuscitation

We assumed a 15 min response interval for HEMS arrival. This may be optimistic in many cases, but exact numbers for this interval remain unavailable in NORCAR. The pilot study [17] demonstrated that the REBOA procedure takes approximately 12 min to perform in a pre-hospital setting. In addition to HEMS response time and time to establish ACLS (airway management, mechanical chest compression machine and intravenous/intraosseous access on the upper body), we estimated that only patients receiving CPR for $>30$ min are eligible. The ambulance response time and
HEMS response time are arbitrarily set by the authors opinions.

In the group of patients with CPR duration of 15-29 min, one-half achieved ROSC (48\%), and for the rest, CPR efforts were terminated for unknown reasons before $30 \mathrm{~min}$. Some of these patients might be eligible for the REBOA procedure if the HEMS response interval were shorter, and if the procedure could be performed faster, or in parallel with other ACLS interventions.

The initial rhythm was VF/VT in $38 \%$ of the eligible cases. This is a higher proportion than in the general

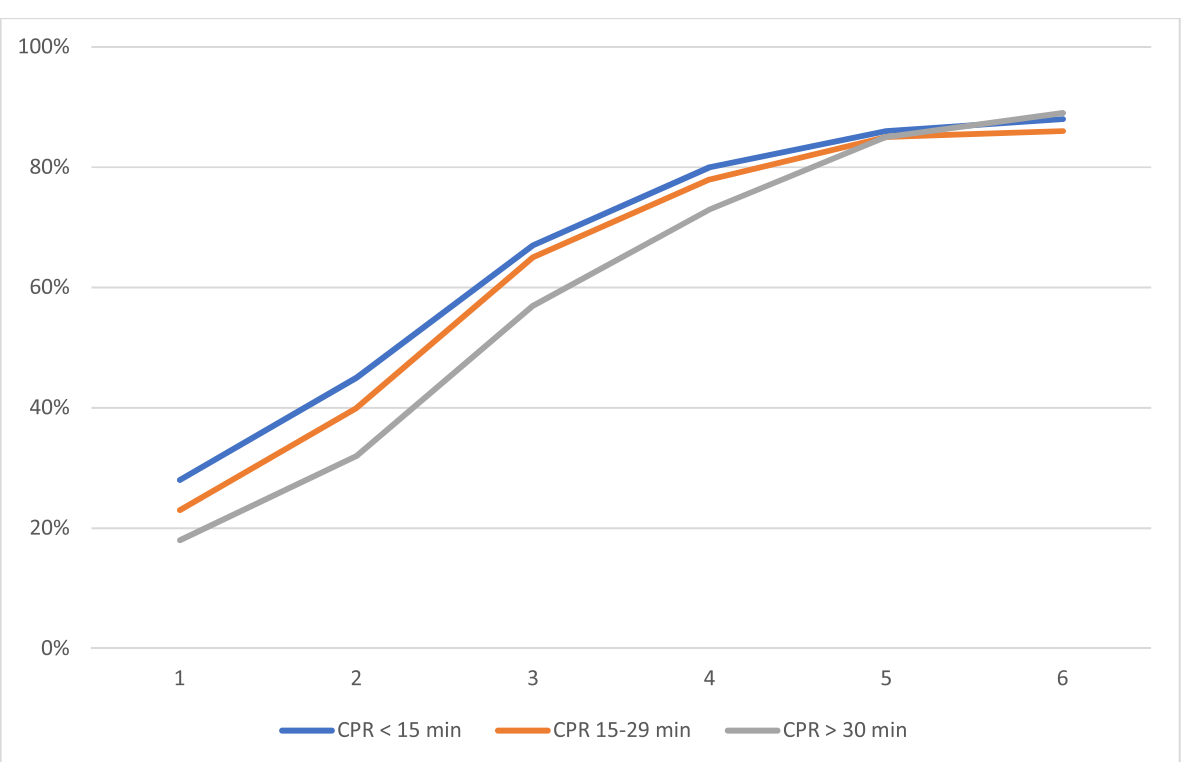

Fig. 3 Cumulative distribution of centrality class in the three subgroups. Centrality class 1 is most central, class 6 is least central. CPR, cardiopulmonary resuscitation 


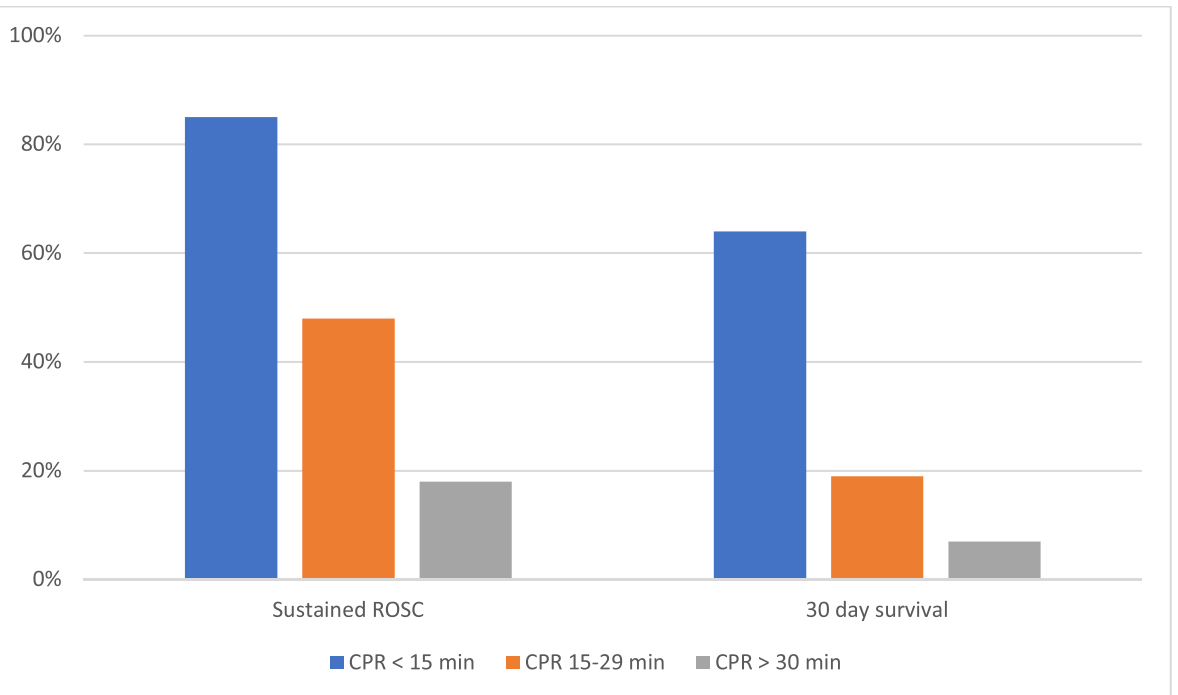

Fig. 4 30-day survival and ROSC in the three subgroups. CPR, cardiopulmonary resuscitation. ROSC, return of spontaneous circulation

OHCA population, as expected and in accordance with the recommendations from the Norwegian Resuscitation Council. We chose to include non-shockable initial rhythms as possible inclusion criteria for pre-hospital REBOA. For this group, the results of conventional treatment are generally poor and new interventions that may improve aortic blood pressures could be especially beneficial. NORCAR do not have information about changes in cardiac rhythm during resuscitation, specifically, what cardiac rhythm presented at the possible time of REBOA inclusion.

A gap analysis compares current knowledge or practice to potential or desired performance. In a medical context a better phrase is needs assessment, where systematic analyses may identify changes in practice to optimize treatment. A description of a health problem allow optimal allocation of resources to improve the health in a population $[33,34]$. It can be tempting to implement new and innovative interventions, but some of these might be resource intensive, carry potential hazards for patients, not properly tested for effect or they may divert focus from well-documented conventional treatment. It is therefore important to perform a needs assessment [33] before any new intervention is universally tested for effect on outcome. A needs assessment may provide the number of patients eligible for inclusion of a specific procedure, e.g. REBOA as an adjunct treatment in non-traumatic OHCA.

Pre-hospital REBOA procedure is shown to be feasible during ACLS, with preserved ACLS quality [17]. This was performed by a standard Norwegian HEMS crew, after completion of a structured training program [35]. The Norwegian HEMS include anaesthesiologists and are regularly part of the resuscitation team at OHCA
[36]. This provides a pre-hospital competency in establishing central vascular lines using Seldinger technique [37]. Services without this competence in the field may not easily be able to perform a pre-hospital REBOA procedure. A structured educational program and regular procedural training is essential for procedural success. With 18 HEMS bases and approximately 240 eligible patients each year, it is not likely that all Norwegian HEMS bases should be trained in this procedure. Most patients are in areas with high centrality index and we therefore argue that only the most central HEMS bases should receive this comprehensive educational program [35].

\section{Limitations}

This study has several limitations. First, it is mandatory to register OHCA to the registry, but some missing inclusion is nevertheless likely. One Swedish study report that as many as $25 \%$ of OHCA was not reported to the Swedish Cardiac Arrest Registry [38]. This is a possible cause of selection bias. Further, there are no data from resuscitations performed at nursing homes unless an EMCC was contacted and no data from out-of-hours primary health care centers unless an EMCC was contacted. These two groups normally constitute only a small number each year, and generally holds a poor prognosis. Second, this is a needs assessment solely based on one database review, thereby only providing an estimate of index cases. The lack of data on actual involvement of HEMS-crew in treatment and their response intervals necessitated some assumptions. However, the registry is nation-wide, and we would argue that because of the solidity of the data, the number of eligible patients is likely to be clinically accurate. Third, NORCAR is a live database and all local clerks 
can add or amend cases. Therefore, the data set may change slightly even for historical data, but expected changes are minimal. Fourth, 277 of the 2241 patients with possible inclusion, had missing data on CPR duration, this constitutes $12 \%$. We decided not to perform multiple imputation [39] as by NORCAR experience the missing data is not missing at random. Fifth, we selected only cases with a suspected non-traumatic aetiology. Some of the patients in the "strangulation" category could be due to a high energy injury/strangulation and should therefore be deemed as a traumatic cardiac arrest. The suspected aetiology is as perceived by the health providers present on scene and may differ from results after autopsy, e.g. is the presumed cause overdose/intoxication (Table 2) which can be related to hypoxia rather than the intoxication itself. Autopsy after deaths outside hospitals are rare in Norway. Sixth, the result of our needs assessment is based on a Norwegian cardiac arrest registry and the Norwegian physicianmanned HEMS structure. This may not be generalizable to other nations, with different population distribution or different policies and cultures for "end-of-resuscitation" decisions. Last, a major challenge in the prehospital setting is weather and light conditions, temperature and amount of space available around the patient, as well as availability of HEMS crew. This may impact on the number of potential candidates that are truly eligible for the procedure. This is well-known operational factor in pre-hospital care but is currently impossible to adjust for in this registry study.

\section{Conclusions}

This analysis of data from a national registry constitutes a needs assessment of the REBOA procedure on OHCA. We found that each year approximately 240 patients, or 9\% of the total ambulance treated OHCA in Norway may potentially be eligible for a pre-hospital REBOA procedure as an adjunct treatment to standard resuscitation. This patient cohort have $18 \%$ ROSC rate and $7 \%$ 30-day survival rate. Most of these patients are in central areas, with only $16 \%$ in non-central areas. This need assessment suggests that there is sufficient patient population in Norway to study REBOA as an adjunct treatment in non-traumatic OHCA. This is the first study to use national cardiac registry data to this purpose.

\footnotetext{
Abbreviations

ACLS: Advanced cardiovascular life support; CA: Cardiac arrest; CPR: Cardiopulmonary resuscitation; EMCC: Emergency medical communications center; HEMS: Helicopter emergency medical service; NORCAR: Norwegian cardiac arrest registry; OHCA: Out of hospital cardiac arrest; REBOA: Resuscitative endovascular balloon occlusion of the aorta; ROSC: Return of spontaneous circulation
}

\section{Acknowledgements}

We wish to thank the Norwegian Cardiac Arrest Registry for their help and patience during the data collection.

\section{Authors' contributions}

JRB designed the study. JKJ extracted and analyzed data. JRB, MR and JKJ interpreted the data. JRB drafted the manuscript and prepared the figures/ Tables. MR and JKJ contributed to the design of the study and revised the manuscript. All authors read and approved the final manuscript.

\section{Funding}

The study is funded by the Norwegian Air Ambulance Foundation. The contributions from other personnel is agreed upon without any financial compensation.

\section{Availability of data and materials \\ The data that support the findings of this study are available from the Norwegian Cardiac Arrest Registry, but restrictions apply to the availability of these data, which were used under license for the current study, and so are not publicly available. Data are however available from the authors upon reasonable request and with permission of the Norwegian Cardiac Arrest Registry}

\section{Ethics approval and consent to participate}

NORCAR can extract and prepare aggregated, anonymous results without further ethical approval. A NORCAR administrator (JKJ) extracted, recoded and aggregated the data on request from the main author (Norwegian Institute of Public Health, ref.nr HKR 19-0149).

\section{Consent for publication}

Not applicable.

\section{Competing interests}

Dr. Jostein Rødseth Brede and Dr. Marius Rehn are partly employed for research purpose in the Norwegian Air Ambulance Foundation. Dr. Jo Kramer-Johansen is employed by the Norwegian National Advisory Unit for Pre-hospital Emergency Care, running the Norwegian Cardiac Arrest Registry.

\section{Author details}

'Department of Emergency Medicine and Pre-Hospital Services, St. Olav University Hospital, Trondheim, Norway. ${ }^{2}$ Norwegian Air Ambulance Foundation, Department of Research and Development, Oslo, Norway. ${ }^{3}$ Department of Anesthesiology and Intensive Care Medicine, St. Olav's University Hospital, Prinsesse Kristinas Gate 3, 7030 Trondheim, Norway. ${ }^{4}$ Department of Circulation and Medicallmaging, Faculty of Medicine and Health Sciences, Norwegian University of Science and Technology (NTNU), Trondheim, Norway. ${ }^{5}$ Division of Prehospital Services, Air Ambulance Department, Oslo University Hospital, Oslo, Norway. ${ }^{6}$ Norwegian National Advisory Unit for Prehospital Emergency Care (NAKOS), Oslo, Norway. ${ }^{7}$ Institute of Clinical Medicine, Faculty of Medicine, University of Oslo, Oslo, Norway. ${ }^{8}$ Faculty of Health Sciences, University of Stavanger, Stavanger, Norway.

Received: 20 January 2020 Accepted: 13 April 2020

Published online: 21 April 2020

\section{References}

1. Tjelmeland IBM, Nilsen JE, Kramer-Johansen J, Andersson L-J, Bratland S, Hafstad AK, et al. Norsk hjertestansregister, Et register over gjenopplivningsforsøk i Norge. [Norwegian Cardiac Arrest Registry, a Registry of Resuscitation Attempts in Norway, yearly report 2017]. 2018;71.

2. Hirlekar G, Jonsson M, Karlsson T, Hollenberg J, Albertsson P, Herlitz J. Comorbidity and survival in out-of-hospital cardiac arrest. Resuscitation. 2018;133:118-23.

3. Daley J, Morrison JJ, Sather J, Hile L. The role of resuscitative endovascular balloon occlusion of the aorta (REBOA) as an adjunct to ACLS in nontraumatic cardiac arrest. Am J Emerg Med. 2017 May;35(5):731-6.

4. Osborn LA, Brenner ML, Prater SJ, Moore LJ. Resuscitative endovascular balloon occlusion of the aorta: current evidence. Open Access Emerg Med OAEM. 2019:11:29-38.

5. Sesma J, Sara MJ, Espila JL, Arteche A, Saez MJ, Labandeira J. Effect of intraaortic occlusion balloon in external thoracic compressions during CPR in pigs. Am J Emerg Med. 2002;20(5):453-62.

6. Nozari A, Rubertsson S, Wiklund L. Improved cerebral blood supply and oxygenation by aortic balloon occlusion combined with intra-aortic 
vasopressin administration during experimental cardiopulmonary resuscitation. Acta Anaesthesiol Scand. 2000;44(10):1209-19.

7. Nozari A, Rubertsson S, Wiklund L. Intra-aortic administration of epinephrine above an aortic balloon occlusion during experimental CPR does not further improve cerebral blood flow and oxygenation. Resuscitation. 2000; 44(2):119-27.

8. Gedeborg R, Rubertsson S, Wiklund L. Improved haemodynamics and restoration of spontaneous circulation with constant aortic occlusion during experimental cardiopulmonary resuscitation. Resuscitation. 1999;40(3):17180.

9. Barton C, Manning JE, Batson N. Effect of selective aortic arch perfusion on median frequency and peak amplitude of ventricular fibrillation in a canine model. Ann Emerg Med. 1996;27(5):610-6.

10. Manning JE, Murphy CA, Hertz CM, Perretta SG, Mueller RA, Norfleet EA. Selective aortic arch perfusion during cardiac arrest: a new resuscitation technique. Ann Emerg Med. 1992;21(9):1058-65.

11. Paradis NA, Rose MI, Gawryl MS. Selective aortic perfusion and oxygenation: an effective adjunct to external chest compression-based cardiopulmonary resuscitation. J Am Coll Cardiol. 1994;23(2):497-504.

12. Paradis NA, Martin GB, Rivers EP, Goetting MG, Appleton TJ, Feingold M, et al. Coronary perfusion pressure and the return of spontaneous circulation in human cardiopulmonary resuscitation. JAMA. 1990;263(8):1106-13.

13. Nozari A, Rubertsson S, Gedeborg R, Nordgren A, Wiklund L. Maximisation of cerebral blood flow during experimental cardiopulmonary resuscitation does not ameliorate post-resuscitation hypoperfusion. Resuscitation. 1999; 40(1):27-35

14. Spence PA, Lust RM, Chitwood WR, lida H, Sun YS, Austin EH. Transfemoral balloon aortic occlusion during open cardiopulmonary resuscitation improves myocardial and cerebral blood flow. J Surg Res. 1990;49(3):217-21.

15. Suzuki A, Taki K, Kamiya K, Miyake T. Cerebral blood flow during open-chest cardiac massage with occlusion of the descending aorta in dogs. Resuscitation. 1985;13(1):69-75.

16. Gedeborg R. C:son Silander H, Rubertsson S, Wiklund L. cerebral ischaemia in experimental cardiopulmonary resuscitation - comparison of epinephrine and aortic occlusion. Resuscitation. 2001;50(3):319-29.

17. Rødseth BJ, Thomas L, Pål K, Aardal SE, Trond N, Edmund S, et al. Feasibility of pre-hospital resuscitative endovascular balloon occlusion of the aorta in non-traumatic out-of-hospital cardiac arrest. J Am Heart Assoc. 2019;8(22): e014394.

18. Dumas RP, Holena DN, Smith BP, Jafari D, Seamon MJ, Reilly PM, et al. Resuscitative endovascular balloon occlusion of the aorta: assessing need in an urban trauma center. J Surg Res. 2019;233:413-9.

19. Barnard EBG, Morrison JJ, Madureira RM, Lendrum R, Fragoso-Iñiguez M, Edwards A, et al. Resuscitative endovascular balloon occlusion of the aorta (REBOA): a population based gap analysis of trauma patients in England and Wales. Emerg Med J EMJ. 2019;32(12):926-32.

20. Morrison JJ, Ross JD, Rasmussen TE, Midwinter MJ, Jansen JO. Resuscitative endovascular balloon occlusion of the aorta: a gap analysis of severely injured UK combat casualties. Shock Augusta Ga. 2014;41(5):388-93.

21. von Elm E, Altman DG, Egger M, Pocock SJ, Gøtzsche PC, Vandenbroucke JP. The strengthening the reporting of observational studies in epidemiology (STROBE) statement: guidelines for reporting observational studies. Lancet. 2007;370(9596):1453-7.

22. Høydahl E. Ny sentralitetsindeks for kommunene. [Centrality index for Norwegian municipalities.] Statistics Norway. 2017. https://www.ssb.no/ befolkning/artikler-og-publikasjoner/sentralitetsindeks-for-kommunene. Accessed 15 May 2019.

23. Ajam K, Gold LS, Beck SS, Damon S, Phelps R, Rea TD. Reliability of the cerebral performance category to classify neurological status among survivors of ventricular fibrillation arrest: a cohort study. Scand J Trauma Resusc Emerg Med. 2011;19(1):38

24. Rittenberger JC, Raina K, Holm MB, Kim YJ, Callaway CW. Association between cerebral performance category, modified Rankin scale, and discharge disposition after cardiac arrest. Resuscitation. 2011;82(8):1036-40.

25. Guru V, Verbeek PR, Morrison LJ. Response of paramedics to terminally ill patients with cardiac arrest: an ethical dilemma. CMAJ. 1999;161(10):1251-4.

26. Mutter EL, Abella BS. Duration of cardiac arrest resuscitation: deciding when to "call the code.". Circulation. 2016:133(14):1338-40.

27. Norsk Resuscitasjonsråd. Guidelines for resuscitation. [Norwegian Resuscitation Council.] 2015. https://nrr.org/no/retningslinjer/norskeretningslinjer-2015. Accessed 9 Sept 2019.
28. Druwé P, Monsieurs KG, Piers R, Gagg J, Nakahara S, Alpert EA, et al. Perception of inappropriate cardiopulmonary resuscitation by clinicians working in emergency departments and ambulance services: the REAPPROPRIATE international, multi-Centre, cross sectional survey. Resuscitation. 2018;132:112-9.

29. Beesems SG, Blom MT, van der Pas MHA, Hulleman M, van de Glind EMM, van Munster BC, et al. Comorbidity and favorable neurologic outcome after out-of-hospital cardiac arrest in patients of 70 years and older. Resuscitation. 2015:94:33-9.

30. Goto Y, Funada A, Goto Y. Relationship between the duration of cardiopulmonary resuscitation and favorable neurological outcomes after out-of-hospital cardiac arrest: a prospective, nationwide, population-based cohort study. J Am Heart Assoc. 2016;5(3):e002819.

31. Division for population statistic. Population, 1 January 2019. Statistics Norway. 2019. https://www.ssb.no/befolkning/statistikker/folkemengde/aarper-1-januar/2019-02-22. Accessed 6 May 2019.

32. Johnsen AS, Sollid SJM, Vigerust T, Jystad M, Rehn M. Helicopter emergency medical services in major incident management: a national Norwegian cross-sectional survey. PLoS One. 2017;12(2):e0171436.

33. Wright J, Williams R, Wilkinson JR. Development and importance of health needs assessment. BMJ. 1998;316(7140):1310-3.

34. Golden SH, Hager D, Gould LJ, Mathioudakis N, Pronovost PJ. A gap analysis needs assessment tool to drive a care delivery and research agenda for integration of care and sharing of best practices across a health system. Jt Comm J Qual Patient Saf. 2017;43(1):18-28.

35. Brede JR, Lafrenz T, Krüger AJ, Søvik E, Steffensen T, Kriesi $C$, et al. Resuscitative endovascular balloon occlusion of the aorta (REBOA) in nontraumatic out-of-hospital cardiac arrest: evaluation of an educational programme. BMJ Open. 2019;9(5):e027980.

36. Krüger AJ, Skogvoll E, Castrén M, Kurola J, Lossius HM. Scandinavian prehospital physician-manned emergency medical services-same concept across borders? Resuscitation. 2010;81(4):427-33.

37. Sollid SJ. M, Rehn M. the role of the anaesthesiologist in air ambulance medicine. Curr Opin Anaesthesiol. 2017;30(4):513-7.

38. Strömsöe A, Svensson L, Axelsson ÅB, Göransson K, Todorova L, Herlitz J. Validity of reported data in the Swedish cardiac arrest register in selected parts in Sweden. Resuscitation. 2013;84(7):952-6.

39. Sterne JA, White IR, Carlin JB, Spratt M, Royston P, Kenward MG, Wood AM, Carpenter JR. Multiple imputation for missing data in epidemiological and clinical research: potential and pitfalls. Bmj. 2009;338:b2393.

\section{Publisher's Note}

Springer Nature remains neutral with regard to jurisdictional claims in published maps and institutional affiliations.
Ready to submit your research? Choose BMC and benefit from:
- fast, convenient online submission
- thorough peer review by experienced researchers in your field
- rapid publication on acceptance
- support for research data, including large and complex data types
- gold Open Access which fosters wider collaboration and increased citations
- maximum visibility for your research: over $100 \mathrm{M}$ website views per year
At BMC, research is always in progress.
Learn more biomedcentral.com/submissions 